Ambient Science, 2018: Vol. 05(Sp1); 97-101

DOI:10.21276/ambi.2018.05.sp1.ra11

ambient

SCIENCE

\title{
The Role of Music on the Delirium in Traumatic Patients: A Case Study in the ICU of Peymanieh Hospital of Jahrom, Fars Province, Iran
}

\section{Mohammad Hasan Damshens', Mohammad Sadegh Sanie', Shohre Javadpour ${ }^{2}$, Mohammad Ali Khaef ${ }^{3}$, Ahmad Rastgarian $^{1 *}$}

'Department of Anesthesiology, Critical Care and Pain Management Research Center, Jahrom University of Medical Sciences, Jahrom, Iran.

${ }^{2}$ Department of Nursing, Jahrom University of Medical Sciences, Jahrom, Iran.

${ }^{3}$ Student Research Committee, Jahrom University of Medical Sciences, Jahrom, Iran

Study Area:Jahrom, Iran

Coordinates: $28^{\circ} 30^{\prime} \mathrm{oo}^{\prime \prime} \mathrm{N} ; 53^{\circ} 33^{\prime} 38^{\prime \prime} \mathrm{E}$

Key words: Music therapy, Acetaminophen, Diclofenac, Ketorolac, Indomethacin, Morphine, Pethidine, Methadone, Fentanyl

Approved by the Research Council and Ethics Committee of Jahrom University of Medical Sciences (IR.JUMS.REC.1394.176).

\section{Introduction:}

Around the world every year, several people victimized by various critical diseases and need ICU care. Apart from their own illness, patients also faced with severe stressors in the ICU environment, such as painful actions, multidrug treatments, mechanical ventilation, and inability to properly communicate (Svenningsen et al., 2015). Long stay in the ICU could develop some long-term psychiatric effects in the patients (Azimi et al., 2015; Mishra et al., 2011), one of the most common symptoms of which is delirium. In fact, delirium is often overlooked syndrome characterized by acute oscillations in the mental state including confusion, neglect, and discordant thinking. The symptoms of delirium in ICU patients seen in between 16\% and 92\% (Azimi et al., 2015; Grandi et al., 2011; Taipale et al., 2012; Mattar et al., 2013) and patients diagnosed with delirium are always at risk for instant like falling, uncontrolled removal of catheters and lines, pneumonia, bedsores, and reaction to medications used to control amnesia and turmoil (Azimi et al., 2015; Pisan et al., 2010;

\section{Abstract}

Delirium is a common syndrome in traumatic patients hospitalized in the ICU, suffering from various physical and psychological complications and increases the mortality and length of stay. Music therapy is a non-medical intervention whose safe courses can be used as a low-cost and effective way to check and treat delirium. In this study, 8 o traumatic patients hospitalized in the ICU of Peymanieh Hospital of Jahrom, Fars Province were randomly and equally assigned to two groups; test and control. Music therapy was treated for patients of the test group twice a day for 45 minutes and those in the control group only received conventional care in the ICU. All patients were examined in terms of delirium, vital signs, the dose and type of medications used to control pain and delirium, and duration of mechanical ventilation in every nursing shift. The results showed that there was no signif icant difference between the test and control groups in terms of delirium but the mean amount of acetaminophen and diclofenac used to check and treat delirium in the test group was significantly lower than that of the control group. Conclusively music therapy could be safely referred to delirium patients to decrease the need for acetaminophen and diclofenac.

Neagoe, 2013; Sadananda et al., 2013). Obviously, delirium can prolong the length of stay in the ICU and hospital and increase mortality rate, healthcare costs, the need for postdischarge nursing care, and risk of cognitive disorders. Moreover, delirium can increase the incidence of PTSD disorders and depression after discharge from the ICU (Azimi et al., 2015). Based on the Diagnostic and Statistical Manual of Mental Disorders, 5th Edition (DSM-5), delirium inclusion criteria are as follows: disturbance in attention and consciousness as a sharp deviation from the baseline (usually hours to a few days) and an additional disturbance in cognition (e.g. memory deficit, disorientation, language, etc.) (APA, 2013). Some of the actions that can be taken to check and treat delirium in ICU patients include adequate pain management, sufficient patient hydration, scheduled patient movement, and timely removal of catheters (Bruno \& Warren, 2010). As per the World Federation of Music Therapy (WFMT) (Li et al., 2015), music therapy is a nonmedical intervention defined as the professional use of 
music and its elements to improve the quality of life and health in the field of medicine, education, and so on. Presently, experimental music therapy techniques have been classified by the World Health Organization (WHO) and the National Institutes of Health (NIH) as one of the complementary and alternative therapies for harmonizing the mind and body. Studies have shown that light music is greatly associated with peace and pleasure, while provocative music triggers tension, anger, and rude behaviors (Mohammadi \& Poladi, 2012). According to Ornstein \& Sobel (1989), music can reduce blood pressure and stress and control immunosuppressive hormones. It was already reported that the music remarkably reduces the anxiety level of patients in preoperative conditions and its effect is greater than oral administration of midazolam (Trappe, 2012). Light music is more benef icial for patients, whereas techno music or heavy metal is dangerous and can cause stress or life-threatening arrhythmias (Trappe, 2012). In another study conducted by McCaffrey \& Locsin (2006) reported reduced pain and acute confusion, increased mobility and satisfaction of patients while determining the effects of listening to music on pain and acute confusion in elderly patients after a knee or hip surgery. Considering the consequences of delirium in the ICU for patients and the medical staff and also the reported effects of music therapy on the improvement of mental state, the present research aims to study the effects of music therapy on the incidence of delirium in patients hospitalized in the ICU.

\section{Methodology:}

The present research was a randomized clinical trial that was conducted in the ICU of Peymanieh Hospital of Jahrom, Fars Province, in between the year March 2016 to March 2017. In this study, 8o traumatic patients hospitalized in the ICU of Peymanieh Hospital of Jahrom were selected as the sample. The inclusion criteria were as follows: i) being aged over 15 , hospitalization in the trauma service, consent of the patient or his/her next of kin, ii) no history of cognitive impairment, depression, taking psychotropic drugs, drug abuse, and alcohol abuse, iii) non-affliction with visual or hearing losses. The exclusion criteria also included hospitalization in the ICU for less than 48 hours and the unwillingness of the patient or his/her next of kin to continue music therapy (For patients who were unable to fill the consent form due to reduced consciousness, the informed consent form was obtained from their next of kin). The music tracks used for music therapy (mainly instrumental music) were selected by a music expert. It is noteworthy that the duration of each music therapy intervention was equal to 45 minutes following the relevant earlier studies (Almerud \& Peterson, 2003; Johnson, 2003; Lai, 2005; Mottaghi et al., 2016). At the beginning of the study, all the ICU nurses attended a two-session training course on the examination of patients using Richmond Agitation-Sedation Scale (RASS) and Confusion Assessment Method for ICU (CAMICU), then, to gain enough skill, trained nurses examined the patients in terms of delirium for one week. We monitored the accuracy of patients' assessment by nurses using RASS AND CAM-ICU and the results. RASS included the following degrees: unarousable, deep sedation, moderate sedation, light sedation, drowsy, alert and calm, restless, agitated, very agitated, and combative. In the case of obtaining a score of above -4 on RASS, patients were assessed in terms of delirium using CAMICU. Finally, patients were assigned into two groups of 40 (test and control). Music therapy was treated to the patients of the testing group for twice a day (once in the morning and once at night) for 45 minutes and those in the control group only received conventional care in the ICU. All the patients were examined in terms of delirium, GCS, vital signs (heart rate, respiratory rate, and arterial oxygen saturation), the dose and type of medications used to control pain and delirium, and duration of mechanical ventilation in every nursing shift (Appendix 2-A). To determine patients' conditions at the admission to the ICU, APACHE-IV scores were calculated for all patients in the first 24 hours of admission. Based on this scale we estimated, the higher the score, the worse the patient's conditions. The data were statistically analyzed using independent t-test, Mann-Whitney U test, and chi-square in SPSS-21.

\section{Results:}

In this study, 8o traumatic patients hospitalized in the ICU were randomly assigned to two groups, including 36 males (90\%) and 4 females (10\%) in the test group and 38 males (95\%) and 2 females (5\%) in the control group. Based on chi-square, the two groups were matched in gender $\left(\mathrm{p} \geq 0.432, \mathrm{df}=1, \mathrm{X}^{2}=1.409\right)$. Therefore, gender, that could have been a confounding factor in the study due to the higher incidence of delirium in men, presented no signif icant difference between the two groups (Table-1).

Table-1: Gender-based frequency distribution of patients in the test and control groups by 'chi-square test $(\mathrm{p} \geq 0.432)^{\prime}$

\begin{tabular}{lllllll}
\hline $\begin{array}{l}\text { Group } \\
\text { Gender }\end{array}$ & \multicolumn{2}{l}{ Test Group } & \multicolumn{2}{c}{ Control Group } & \multicolumn{2}{c}{ Total Group } \\
& Frer. & P* & Freq. ${ }^{*}$ & Per. ${ }^{* *}$ & Freq. ${ }^{*}$ & Per. ${ }^{* *}$ \\
\hline Male & 36 & 90 & 38 & 95 & 72 & 80 \\
female & 4 & 10 & 2 & 5 & 8 & 20
\end{tabular}

${ }^{*}$ Frequency, ${ }^{* *}$ Percent

The mean age of patients was equal to $34.6 \pm 17.67$ in the test group and $33.95 \pm 15.06$ in the control group ( $\mathrm{p} \geq 0.860)$. Since the age of over 65 is considered a risk factor for delirium, the participants were classif ied into two groups over 65 years and under 65 years and compared to each other in terms of the incidence of delirium. The results showed that out of the 4 patients aged over 65 years, 2 patients $(50 \%)$ were afflicted with delirium. In addition, 
out of the 76 patients aged under 65 years, 29 patients (38.15\%) had exhibited delirium and 47 of them (61.75\%) did not shown any symptom of the same. The results of chisquare indicated that there was no significant difference between the two age groups in the incidence of delirium $(\mathrm{p} \geq 0.639)$. In terms of the relationship between gender and delirium, 4 of the female patients (57.1\%) and 27 of the male patients $(37 \%)$ were afflicted with delirium. Although the incidence of delirium was higher in females, no statistically significant difference was observed between men and women in this regard $(\mathrm{p} \geq 0.421, \mathrm{df}=1$, $\left.\mathrm{X}_{2}=1.093\right)$. APACHE-IV score was calculated for all patients and the results demonstrated that there was no signif icant difference between the two groups in this regard ( $\mathrm{p} \geq 0.105)$ (Table-2).

Table-2: Comparison between control and test groups of patients in terms of the mean score of APACHE-IV, 't-test'

\begin{tabular}{llll}
\hline Group & Total patients & Mean score & p-value \\
\hline Test & 40 & $30.12 \pm 14.06$ & \\
Control & 40 & $35.67 \pm 16.13$ & 0.105 \\
\hline
\end{tabular}

Based on the study results, 15 patients in the test group (37.5\%) and 16 patients in the control group (40\%) were afflicted with delirium. These figures present no significant difference between the two groups ( $\mathrm{p}>0.818, \mathrm{df}=1, \mathrm{X}_{2}=0.053$ ) (Table- 3 ).

Table-3: Comparison between control and test groups of patients in terms of the mean score of APACHE-IV, 't-test' ( $\mathrm{p} \geq 0.818$ )

\begin{tabular}{llll}
\hline Group & $\begin{array}{l}\text { Total } \\
\text { patients }\end{array}$ & $\begin{array}{l}\text { Affliction } \\
\text { with delirium }\end{array}$ & $\begin{array}{l}\text { Non-affliction } \\
\text { with delirium }\end{array}$ \\
\hline Test & 40 & $15(37.5 \%)$ & $25(62.5 \%)$ \\
Control & 40 & $16(40 \%)$ & $24(60 \%)$ \\
Total & 80 & $31(38.8 \%)$ & $49(61.3 \%)$ \\
\hline
\end{tabular}

The results showed that patients in the test group were under mechanical ventilation in the ICU for $28.32 \pm 12.15$ hours, on average, whereas this figure for the control group was 63.02 \pm 24.6 . Therefore, music therapy clinically reduced the duration of mechanical ventilation in patients, but the difference between the two groups was not statistically signif icant ( $\mathrm{p} \geq 0.958)$ (Table-4).

Table-4: Comparison between control and test groups of patients in the duration of mechanical ventilation ' t-test' $(\mathrm{p} \geq 0.258)$

\begin{tabular}{lc}
\hline Group & Mean duration of mechanicalventilation in ICU \\
\hline Test & $28.32 \pm 12.15$ \\
Control & $63.02 \pm 24.6$ \\
\hline
\end{tabular}

The results demonstrated that the mean lengths of staying in the ICU were $6.42 \pm 4.32$ (test group) and 5.5 \pm 3.38 (control groups) days, respectively. Independent t-test showed that there was no significant difference between the two groups in this regard ( $p>0.315)$. Drugs used to relieve pain in the two groups during their hospitalization in the ICU included acetaminophen, diclofenac, ketorolac, indomethacin, morphine, pethidine, methadone, and fentanyl. The study findings indicated that the mean amount of all these drugs, except indomethacin, was higher in the control group. Although the administration of indomethacin was lower in the control group, it presented no significant difference between the two groups $(\mathrm{p}>0.317)$. Among other pain relievers, the mean amount of acetaminophen $(\mathrm{p}<0.014)$ and diclofenac $(\mathrm{p} \leq \mathrm{0.022})$ made a significant difference between the test and control groups (Table-5).

Table-5: Comparison between control and test groups of patients in terms of the mean values of pain relievers

\begin{tabular}{llll}
\hline Pain reliever & Test group & Control group & p-value \\
\hline Morphine & $11.43 \pm 5.19$ & $\mathbf{2 2 . 0 4 + 1 0 . 2 5}$ & $\geq 0.75$ \\
Pethidine & $80.26 \pm 38.13$ & $76.12 \pm 47.5$ & $\geq 0.259$ \\
Acetaminophen $3 \pm 1.41$ & $2.81 \pm 3.55 \pm$ & $\leq 0.014$ \\
Fentanyl & $23.74 \pm 4.1$ & $1.05 \pm 0.38$ & $\geq 0.339$ \\
Indomethacin & $7.91 \pm 1.25$ & $0.0 \pm 0.0$ & $\geq 0.317$ \\
Ketorolac & $0.0 \pm 0.0$ & $8 \pm 2.25$ & $\geq 0.079$ \\
Diclofenac & $0.0 \pm 0.0$ & $88.29 \pm 30$ & $\leq 0.022$ \\
Methadone & $0.0 \pm 0.0$ & $1.58 \pm 0.25$ & $\geq 0.0317$ \\
\hline
\end{tabular}

In this study, haloperidol and midazolam drugs were used to treat delirium in patients hospitalized in the ICU. The results showed that the mean amount of haloperidol and midazolam administered to patients in the test group was lower than that of the control group, but the difference between the two groups was not statistically significant $(p \geq 0.063, p \geq 0.207)$. In this study, vital signs of each patient were measured in every nursing shift and then their mean values were calculated. Data analysis demonstrated that the mean systolic blood pressure in the test group $(129.92 \pm 17.6 \mathrm{mmHg}$ ) was lower than that of the control group $(135.49 \pm 15.82 \mathrm{mmHg}$ ), but it was not significantly different ( $\mathrm{p} \geq 0.14)$. In addition, the mean diastolic blood pressure in the test group $(78.79 \pm 8.58 \mathrm{mmHg})$ was lower than that of the control group $(81.08 \pm 9.04 \mathrm{mmHg})$, but it did not present a significant difference between the groups ( $\mathrm{p} \geq 0.248)$. The mean PR (84.74 \pm 12.64 for the test group and $87.39 \pm 12.47$ for the control group), RR (19.71 \pm 1.79 for the test group and $19.63 \pm 1.56$ for the control group), and $\mathrm{O}_{2}$ saturation ( $97.12 \pm 1.73$ for the test group and $97.61 \pm 0.70$ for the control group) presented no significant difference between the two groups $(\mathrm{p} \geq 0.348, \mathrm{p} \geq 0.825$, and $\mathrm{p} \geq 0.105$, respectively).

\section{Discussion:}

The main objective of this research was to study the effects of music therapy on the cases of delirium in traumatic patients hospitalized in the ICU. The study findings revealed no significant difference between the test and control groups in terms of the incidence of delirium with respect to the music therapy. Although music therapy failed to reduce the incidence of delirium in this study, it did not exacerbate delirium in patients. The tool used in this study to measure delirium was a qualitative scale named CAM-ICU that cannot measure the severity of 
delirium. Therefore, patients were evaluated in terms of delirium only qualitatively in this study. In other words, no differentiation was made between patients who presented delirium several times during their stay in the ICU and those who were diagnosed with delirium only once in this period. Earlier in the cases of acute delirium in elderly patients after a knee or hip surgery, the music therapy was found to be effective in subsiding delirium and confusion (McCaffrey \& Locsin, 2006). The results of the present study showed that the mean duration of mechanical ventilation was equal to 12.1 hours for the test group and 24.6 hours for the control group. Therefore, music therapy clinically reduced the duration of mechanical ventilation in patients, but statistically both the groups revealed no difference. In a similar type of study, the results showed that the mean duration of mechanical ventilation and length of stay in the ICU was lower in patients of the test group (Adrienn et al., 2014). The point to be considered in this study was that the patients had directly gotten the meaning of sentences, hence, the effects of positive thinking sentences would be greater than music therapy on reducing the duration of mechanical ventilation. Our results showed that the mean length of stay in the ICU was 6.4 days for the test group and 5.5 days for the control group, which revealed no signif icant difference. The study findings indicated that the mean amount of all these drugs, except indomethacin, was higher in the control group. Although the administration of indomethacin was lower in the control group, it also did not reveal a signif icant difference between the two groups.

Among other pain relievers, the mean amount of acetaminophen and diclofenac exhibited a significant difference between the test and control groups. In a study aiming at determining the effects of music therapy on anxiety, pain, and the amount of analgesics (especially acetaminophen and NSAIDs) administered to patients undergoing a $C A B G$, the results indicated significant improvements in patients under music therapy (Cigerci \& Özbayir, 2016). In our study, results against the administration of the mean amount of haloperidol and midazolam to the patients belong to the test group was lower than that of the control group, but the difference between the two groups was not statistically significant. In a study, it was seen that the 20 minutes of music therapy led to the reduction of systolic blood pressure, heart rate, and respiratory rate (Jaber et al., 2007). In a study, the mean age of patients with delirium $(69.3 \pm 13.9$ years) was significantly higher than in patients without delirium (63.5 \pm 16.5 years). In addition, there was no significant difference between the two groups in terms of gender (Jang et al., 2016). Based on the results of the present study, although the incidence of delirium in patients aged over 65 years $(50 \%)$ was higher than those aged under 65 years (38.15\%), there was no significant relationship between demographics (age and gender) and the incidence of delirium was evidenced. According to the results of the above study, which was performed on 398 patients, indicating the association between age and the occurrence of delirium, it can be stated that the larger statistical population of this study has led to such a result.

\section{Conclusion:}

In overall, there was no significant relationship between music therapy and the occurrence of delirium in this study. Hence, music therapy can be used as a low-cost and safe tool in order to reduce the need to administer analgesics to traumatic patients hospitalized in the ICU.

\section{Acknowledgment:}

We would like to thank the Clinical Research Development Unit of Peymanieh Educational and Research and Therapeutic Center of Jahrom University of Medical Sciences for providing facilities to this work.

\section{References:}

Almerud, S. \& Peterson, K. (2003): Music Therapy: a complementary treatment for mechanically ventilated intensive care patients. Intensive.Crit Care Nurs., 19(1):21-30.

APA (American Psychiatric Association) (2013): Diagnostic and Statistical manual of mental disorders (fifth edition). Pub. by: American Psychiatric Association Publishing. 991 p.

Azimi, A.V., Ebadi, A., Ahmadi, F., Saadat, S., (2015): Delirium in Prolonged Hospitalized Patients in the Intensive Care Unit Trauma Mon., 20(2): e17874.

Bruno, J.J. \& Warren, M.L. (2010): Intensive care unit delirium. Crit Care Nurs. Clin. NorthAm., 22(2):161-178.

Cigerci, Y. \& Özbayir, T. (2016): The effects of music therapy on anxiety, pain and the amount of analgesics following coronary artery surgery. Turk. Gogus Kalp. Dama., 24(1):44-50.

Grandi, C., Tomasi, C.D., Fernandes, K., Stertz, L., Kapczinski, F., Quevedo, J., Dal-Pizzol, F. \& Ritter, C. (2011): Brain-derived neurotrophic factor and neuron-specie enolase, but not Sioobeta, levels are associated to the occurrence of delirium in intensive care unit patients. L. Crit. Care, 26(2):133-137.

Johnson, J.E. (2003): The use of music to promote sleep in older women. L. Comm. Health Nurs., 20(1):27-35.

Jaber, S., Bahloul, H., Guétin, S., Chanques, G., Sebbane, M. \& Eledjam, J.J. (2007): Effects of music therapy in intensive care unit without sedation in weaning patients versus nonventilated patients. Ann. Fr. Anesth. Reanim., 26(1):30-38.

Jang, S., Jung, K-I., Yoo, W-K., Jung, M.H. \& Ohn, S.H. (2016): Risk Factors for Delirium During Acute and Subacute Stages of Various Disorders in Patients Admitted to Rehabilitation Units. Ann. Rehabil. Med., 40(6):1082-1091.

Lai, H.L. \& Good, M. (2005): Music improves sleep quality in older adults. L.Adv. Nurs., 49(3):234-244.

Li, C.H., Liu, C.K., Yang, Y.H., Chou, M.C., Chen, C.H., Lai, C.L. (2015): Adjunct effect of music therapy on cognition in Alzheimer's disease in Taiwan: a pilot study. Neuropsychiatr. Dis. Treat.,11:291-296.

Mattar, I., Chan, M.F. \& Childs, C. (2013): Risk Factors for Acute 
Delirium in Critically Ill Adult Patients: A Systematic Review. ISRN Critical Care, 2013:Article ID 910125.

McCaffrey, R. \& Locsin, R. (2006): The effect of music on pain and acute confusion in older adults undergoing hip and knee surgery. Holist Nurs Pract. 20(5):218-224.

Mishra, R.K., Alalawi, R., Raj, R. \& Nugent, K.M. (2011): Prolonged acute care in a 52-year-old man with respiratory failure: lessons learned from 70-day intensive care unit hospitalization. LCrit Care., 26(5):532.e9-532.e16.

Mohammadi, A. \& Poladi, F. (2012). An introduction to music, nerves and psyche. Pub. by: Shabahang Publication, Tehran, Iran.

Mottaghi, R., Kamkar, A. \& Maredpoor, A. (2016): Effectiveness of Targeted Musical Therapy on Sleep Quality and Overcoming Insomnia in Seniors. Iran. J. Ageing., 11 (2):348-357.

Neagoe, A.D. (2013): Delirium with manic and psychotic features associated with amantadine. Gen. Hosp. Psychiatry, 35(6):68o.e7-8.

Ornstein, R. \& Sobel, D. (1989): Coming to our Senses. Advances, 6(3):49-56.

Pisani, M.A., Murphy, T.E., Araujo, K.L., Van Ness, P.H. (2010): Factors associated with persistent delirium after intensive care unit admission in an older medical patient population.. . Crit. Care, 25(3):540 e1-7.
Sadananda, S.K., Narayanaswamy, J.C., Srinivasaraju, R. \& Math, S.B. (2013): Delirium during the course of electroconvulsive therapy in a patient on lithium carbonate treatment. Gen. Hosp. Psychiatry, 35(6):678 e1-2

Svenningsen, H., Egerod, I., Christensen, D., Tønnesen, E.K., Frydenberg, M. \& Videbech, P. (2015): Symptoms of Posttraumatic Stress after Intensive Care Delirium. BioMed Res. Int., 2015: Article ID 876947.

Szilagyi, A.K., Dioszeghy, C. Frituz, G., Gál, J., Varga, K. (2014): Shortening the length of stay and mechanical ventilation time by using positive suggestions via $\mathrm{MP}_{3}$ players for ventilated patients. Interv. Med. Appl. Sci., 2 6(1):3-15.

Taipale, P.G., Ratner, P.A., Galdas, P.M., Jillings, C., Manning, D., Fernandes, C. \& Gallaher, J. (2012): The association between nurse-administered midazolam following cardiac surgery and incident delirium: an observational study. Int. J. Nurs. Stud., 49(9):1064-1073.

Trappe, H.J. (2012): Role of music in intensive care medicine. Int. J. Crit. Illn. Inj. Sci., 2(1):27-31. 